\title{
Simulation of Hot Rolling of Steel Using Lead*
}

\section{By Shigeru SHIDA, ,* Hiroshi AWAZUHARA, ${ }^{* *}$ Ken-ichi YASUDA ${ }^{* *}$ and Sukebumi TSUMURA**}

\begin{abstract}
Synopsis
The suitability of lead as a model material for simulation of hot rolling of steel is experimentally demonstrated.

The effect of tension on the rolling load in hot strip rolling of steel is investigated, and the following theoretical formula is proven to agree well with the results of the experimental simulations using lead.

$$
Q_{t}=Q_{0}-(0.5+0.16 r) t_{\mathrm{b}} / k_{m}-(0.5-0.16 r) t_{\mathrm{f}} / k_{m}
$$

where $Q_{t}$ is the rolling load function with tension, $Q_{0}$ is that without tension, $r$ is the reduction, $t_{\mathrm{b}}$ and $t_{\mathrm{f}}$ are the front and the back tension, respectively, and $k_{m}$ is the mean resistance to deformation.

Three-dimensional deformation of a material being rolled is investigated, and the possibility of strip crown control in hot rolling is confirmed.
\end{abstract}

\section{Introduction}

Experimental research concerned with the hot rolling process should ideally be conducted using hot steels as the test material. But hot steel is not tractable in a laboratory because it is difficult to prevent its oxidation and to control its temperature.

There are advantages, such as ease of handling and accuracy of measurement, in using other materials at room temperature. Therefore, plasticine and lead have long been used extensively in the simulation of section steel rolling.

Lead is chosen as the model material in this work, and after examining its similarity to hot steel, several problems associated with the hot rolling process, e.g., the effect of tension on rolling load and three-dimensional deformation of the material being rolled, are experimentally investigated.

\section{Similarity of Lead to Hot Steel}

\section{Similarity with Respect to Rolling Load}

The rolling load $P$ is given by the following equation:

$$
P=k_{m} \cdot b \cdot l_{d} \cdot Q
$$

where $k_{m}$ is the mean resistance to deformation, $b$ the strip width, $l_{d}$ the contact length and $Q$ the rolling load function.

If it is assumed that hot steel (subscript $\mathrm{H}$ ) is similar in every respect to a model material (subscript M) at $1 / \varphi$ scale, then the next equation holds:

$$
P_{\mathrm{H}} / P_{\mathrm{M}}=\varphi^{2} k_{m \mathrm{H}} / k_{m \mathrm{M}}
$$

Therefore, if $k_{m \mathrm{H}}$ and $k_{m \mathrm{M}}$ are known, it is possible to study the rolling load during hot rolling using a model material.
In practice, however, various factors, e.g., the width of spread, roll deflection or friction, may disturb the above similarity condition. For these reasons, possiblities of experimentally simulating the hot rolling process with lead were investigated.

\section{Influence of the Width of Spread}

Given contact lengths $l_{d}$ that are nearly the same, the influence of the width $b$ on the rolling pressure $p_{m}$ is examined. The $p_{m}$ is given by the equation:

$$
p_{m}=\frac{P}{b \cdot l_{d}}=k_{m} \cdot Q
$$

Here, it is to be borne in mind that, for the width $b$, $b_{m}$ which is the mean value of the entry and delivery widths $b_{1}$ and $b_{2}$ is commonly used, and that, when $b_{m}$ is used, the mean rolling pressure tends to assume a lower value, especially when the width is small. It is because that the rolling load does not increase at the same rate as the spread. With increases in the spread, the contact area increases, and that causes rolling load to increase. But, on the other hand, increase in the width also causes the transverse constraint to decrease, causing the rolling pressure to decrease.

Figure 1 shows $p_{m}$ calculated with entry width $b_{1}$ for $b$ of Eq. (3). The results indicate that the use of $b_{1}$ for the width eliminates the influence of the spread on the rolling load, even though the width of the spread increases. The same explanation can be given in the case of lead.

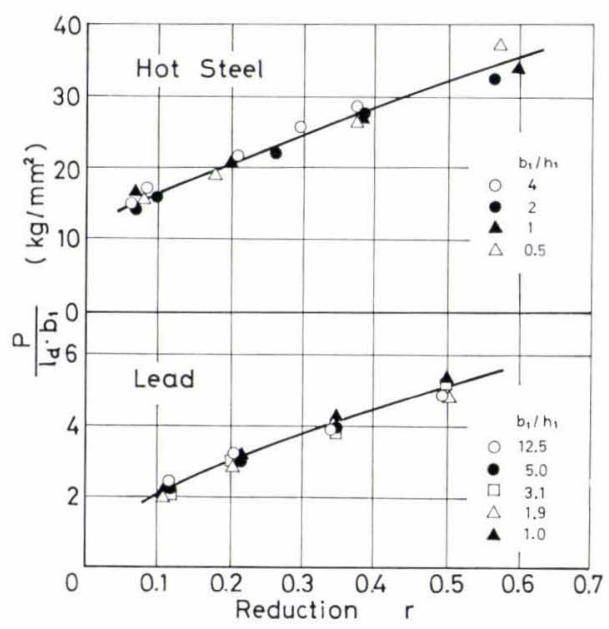

Fig. 1. Effect of width of strip $b_{1} / h_{1}$ on specific rolling pressure

* Originally published in Journal of The Japan Society for Technology of Plasticity, 9 (1968), 796, in Japanese. English version received February 20, 1979.

** Mechanical Engineering Research Laboratory, Hitachi Limited, Kandatsu-cho, Tsuchiura 300. 


\section{Influences of Roll Flattening and Friction between Rolls and Strip}

These influences can be examined by comparing the right side of Eq. (3), $k_{m} \cdot Q$ (calculated rolling pressure), with the left side, $p_{m}$ (observed value). Figure 2, which shows the results that were obtained for $Q$ with Sims' formula, indicates that lead and hot steel are the same in the tendencies. In other words, the study of the rolling load function $Q$ of hot steel is possible in experiments with lead.

\section{Similarity in the Low Reduction Range}

With a low reduction and large thickness, the peening effect is large. It has already been shown that in such a case the rolling load can be expressed by the following formulas, which take into consideration the correspondences between rolling and die pressing. $^{2 \prime}$

$$
\begin{aligned}
& P=k_{m} \cdot b_{1} \cdot l_{d} \cdot \eta \cdot Q_{s d} \\
& \eta=1.0 \quad\left(l_{d} / h_{m} \geqq 1.0\right) \\
& \left.\eta=\frac{3+\left(h_{m} / l_{d}\right)}{3+\left(l_{d} / h_{m}\right)} \quad\left(l_{d} / h_{m}<1.0\right)\right\} \\
& h_{m}=\left(h_{1}+h_{2}\right) / 2 \text {. } \\
& l_{d}=\sqrt{R^{\prime}\left(h_{1}-h_{2}\right)} \\
& Q_{s d}=0.8+\left(\frac{0.052}{r}+0.016\right)\left(\sqrt{\frac{R^{\prime}}{h_{1}}}-0.5\right) \text {. }
\end{aligned}
$$

The result obtained for $\eta$ in calculations with Eq. (4), which use the experimental rolling load, is shown in Fig. 3, where Eq. (5) is represented by the solid line. It will be seen the theoretical values are in good agreement with the experimented ones. Here again, similarity of lead to hot steel is evident even when the peening effect is large.

\section{Similarity in the Material Deformation}

In the discussion which follows, the width of spread of lead and hot steel are compared under the assumption that the friction between rolls and the material being rolled has more of an influence on the deformation of the material than on the rolling load.

When the thickness $h_{1}$ and width $b_{1}$ of a strip becomes $h_{2}$ and $b_{2}$, respectively, after rolling, the spread rate $Y$ is defined as:

$$
Y=\frac{\log _{e}\left(b_{2} / b_{1}\right)}{\log _{e}\left(h_{1} / h_{2}\right)}
$$

where $b_{2}$ represents the mean width calculated from elongation and reduction with the volume constant.

On the assumption that $Y$ is determined only by geometrical parameters under sticking conditions, $Y$ will be considered to be expressed as a function of the following nondimensional factors $\alpha, \beta$, and $\gamma$.

$$
\alpha=l_{a} \mid b_{1}, \quad \beta=h_{1} / b_{1}, \quad \gamma=R / h_{1}
$$

For example, Yanagimoto ${ }^{4)}$ defined $Y$ in the formulas:

$$
Y=f(X)
$$

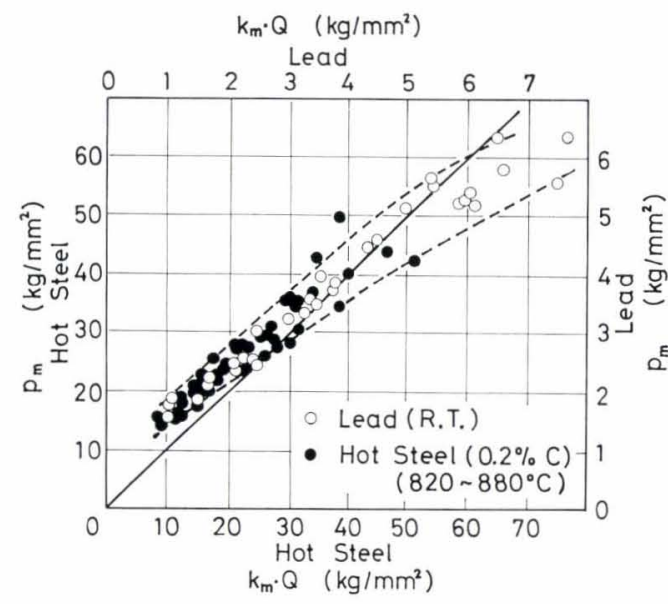

Fig. 2. Similarity of lead and hot steel

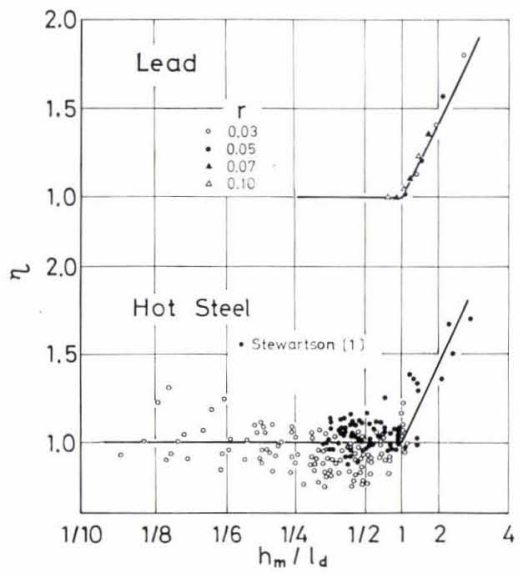

Fig. 3. Relation between $h_{m} / l_{d}$ and $r$

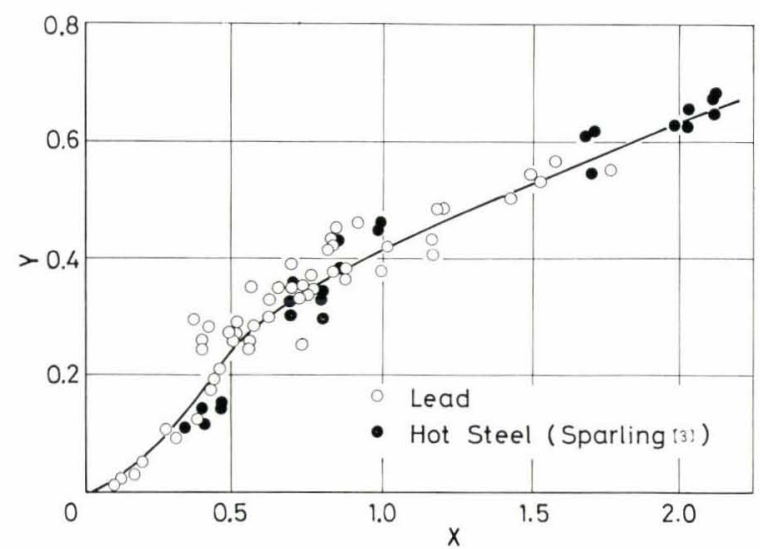

Fig. 4. Comparison of rate of spread between hot steel and model material

$$
X=2 \alpha /(2+\beta)
$$

The relation between $\mathrm{X}$ in Eq. (12) and the experimental values for $Y$ is shown in Fig. 4, which indicates that lead and hot steel are the same in the tendencies.

\section{Simulation of Hot Rolling}

As mentioned above, there are similarities between lead at room temperature, and hot steel with regard to the rolling load and the mean widths of 
spread, and this observation indicates that lead is a suitable material to model the hot rolling process. Using lead strip in a simulation of hot rolling, the influence of tension on the rolling load and the deformation behavior of the strip crown can thus be investigated.

\section{Hot Strip Rolling with Tension}

In strip rolling in a hot tandem mill, tension has not been considered in the rolling load equation, because the tension between stands is always controlled to nearly zero with looper. Actually, however, when a looper is used, a slight tension that effects the rolling load is generated. Moreover, there are plans now to make a positive use of this tension for $\mathrm{AGC}$ during hot rolling. For these reasons, it is better to consider tension in the rolling load equation for hot strip rolling. Theorectical and experimental investigations of the effect of tension on rolling load are discussed in the following sections.

\section{Theoretical Analysis}

The theoretical analysis begins with Sims' method, ${ }^{5)}$ where non-zero back and front tensions are used for the boundary conditions. The equilibrium of forces acting on a small segment of material under the arc of contact is shown in Fig. 5. Von Karman's formula is transformed by assuming sticking and a small angle for $\theta$ to obtain the following equation:

$$
d\left(h_{f}\right) / d \theta=2 R^{\prime} p \theta \pm R^{\prime} k_{m}
$$

where the positive sign applies from the plane of exit to the neutral plane, and the negative sign from the neutral plane to the plane of entry. The yield condition is given as follows.

$$
p-f=\frac{\pi}{4} k_{m}
$$

Substituting Eq. (14) for Eq. (13), and then using Eqs. (15), (16) and (17) is given.

$$
\begin{aligned}
& h=h_{2}+\theta^{2} R^{\prime} \ldots \ldots \ldots \ldots \ldots \ldots \ldots \ldots \ldots \ldots \ldots \ldots \ldots \ldots \ldots \ldots \ldots \ldots \ldots \ldots \ldots \ldots \ldots \ldots \ldots \ldots \ldots \ldots \ldots \ldots \ldots \ldots \ldots \\
& d h / d \theta=2 \theta R^{\prime} \ldots \ldots \ldots \ldots \ldots \\
& \frac{d}{d \theta}\left(\frac{p}{k_{m}}-\frac{\pi}{4}\right)=\frac{R^{\prime} \pi \theta}{2\left(h_{2}+R^{\prime} \theta^{2}\right)} \pm \frac{R^{\prime}}{h_{2}+R^{\prime} \theta^{2}}
\end{aligned}
$$

Integration of Eq. (17) gives :

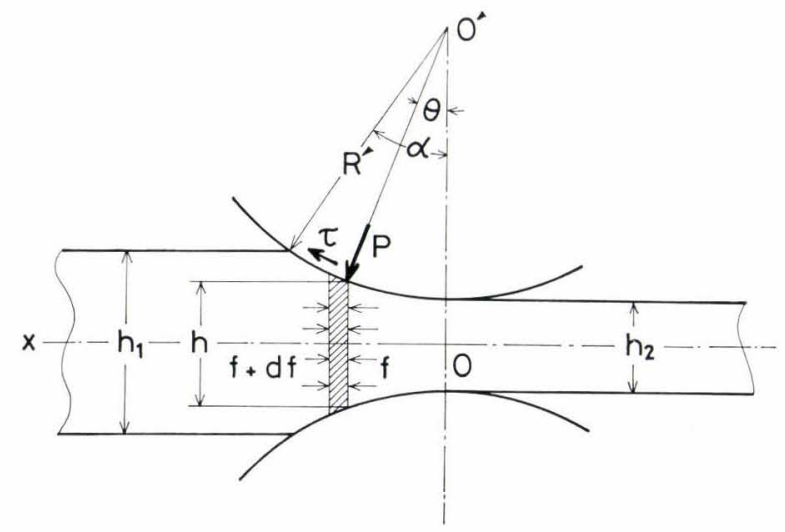

Fig. 5. State of stress in roll bite

$$
\frac{p}{k_{m}}=\frac{\pi}{4} \log _{e} h+\frac{\pi}{4} \pm \sqrt{\frac{R^{\prime}}{h_{2}}} \tan ^{-1}\left(\sqrt{\frac{R^{\prime}}{h_{2}}} \cdot \theta\right)+C
$$

A constant of integration $C$ is given by $f=t_{\mathrm{f}}$ at the exit and by $f=t_{\mathrm{b}}$ at the entrance. Finally, the rolling load function $Q_{\ell}$ in which tension is considered is obtained as :

$$
\begin{aligned}
& Q_{t}= \frac{P}{k_{m} \cdot b \cdot \sqrt{ } R^{\prime}\left(h_{1}-h_{2}\right)} \\
&= \frac{\pi}{2} \sqrt{\frac{1-r}{r}} \tan ^{-1} \sqrt{\frac{r}{1-r}}-\frac{\pi}{4}-\sqrt{\frac{1}{r} \cdot \frac{R^{\prime}}{h_{1}}} \\
& \times \log _{e} \frac{h_{n}}{h_{2}}+\frac{1}{2} \sqrt{\frac{1}{r} \cdot \frac{R^{\prime}}{h_{1}}} \log _{e} \frac{1}{1-r}-\frac{t_{\mathrm{b}}}{k_{m}} \ldots \\
& \log _{e} \frac{h_{n}}{h_{2}}=\log _{e}\left\{1+\tan ^{2}\left(\frac{1}{2} \tan ^{-1} \sqrt{\frac{r}{1-r}}\right.\right. \\
& \quad-\frac{\pi}{8} \sqrt{1-r} \sqrt{\frac{h_{1}}{R^{\prime}}} \log _{e} \frac{1}{1-r} \\
&\left.\left.\quad-\frac{1}{2} \sqrt{ } 1-r \sqrt{\frac{h_{1}}{R^{\prime}}} \frac{t_{\mathrm{b}}-t_{\mathrm{f}}}{k_{m}}\right)\right\} \ldots \ldots \ldots \ldots . . .
\end{aligned}
$$

A Taylor expansion of Eq. (20) gives a method of approximation that is accurate enough for practical use:

$$
\begin{aligned}
\log _{e} \frac{h_{n}}{h_{2}}= & \log _{e}\left\{1+\tan ^{2}\left(\frac{1}{2} \tan ^{-1} \sqrt{\frac{r}{1-r}}\right)\right\} \\
& -\left(\frac{\pi}{4} \log _{e} \frac{1}{1-r}+\frac{t_{\mathrm{b}}-t_{\mathrm{f}}}{k_{m}}\right) \sqrt{ } 1-r \\
& \times \tan \left(\frac{1}{2} \tan ^{-1} \sqrt{\frac{r}{1-r}}\right) \sqrt{\frac{h_{1}}{R^{\prime}}} \ldots .
\end{aligned}
$$

Substituting Eq. (21) for Eq. (19),

$$
\begin{aligned}
Q_{t}= & f_{1}(r) \sqrt{\frac{R^{\prime}}{h_{1}}}+f_{2}(r)-\frac{t_{\mathrm{b}}}{k_{m}}+\frac{t_{\mathrm{b}}-t_{\mathrm{f}}}{k_{m}} f_{3}(r) \ldots(22) \\
f_{1}(r)= & \frac{1}{2} \sqrt{\frac{1}{r}} \log _{e} \frac{1}{1-r}-\sqrt{\frac{1}{r}} \log _{e}\left\{1+\tan ^{2}\right. \\
& \left.\times\left(\frac{1}{2} \tan ^{-1} \sqrt{\frac{1}{1-r}}\right)\right\} \ldots \ldots \ldots \ldots \ldots \ldots \ldots \ldots(2) \\
f_{2}(r)= & \frac{\pi}{2} \sqrt{\frac{1-r}{r}} \tan ^{-1} \sqrt{\frac{r}{1-r}}-\frac{\pi}{4}+\frac{\pi}{4} \sqrt{\frac{1-r}{r}} \\
& \times \log _{e} \frac{1}{1-r} \tan \left(\frac{1}{2} \tan ^{-1} \sqrt{\frac{r}{1-r}}\right) \ldots \ldots . .(2) \\
f_{3}(r)= & \sqrt{\frac{1-r}{r}} \tan \left(\frac{1}{2} \tan ^{-1} \sqrt{\frac{r}{1-r}}\right) \ldots \ldots \ldots \ldots . .
\end{aligned}
$$

As for $f_{1}(r) f_{2}(r)$, it has already been reported that the following equations can be used. ${ }^{2)}$

$$
\begin{aligned}
Q_{0} & =f_{1}(r) \sqrt{\frac{R^{\prime}}{h_{1}}}+f_{2}(r) \\
f_{1}(r) & =0.45 r+0.04 \ldots \ldots \ldots \\
f_{2}(r) & =0.8+0.5 f_{1}(r) \ldots \ldots
\end{aligned}
$$

where $Q_{0}$ is the rolling load function without tension. As for $f_{3}(r)$, Fig. 6 shows the relation between $r$ and $f_{3}$. As can be seen from the figure, changes in $f_{3}$ caused by changes in $r$ are small; this means that withing the bounds of practical reduction, $f_{\mathbf{3}}$ can be approximated as follows: 


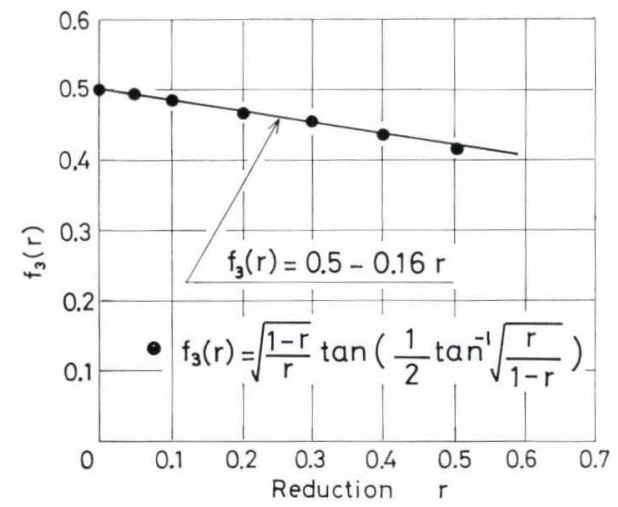

Fig. 6. Relation between reduction and $f_{3}$

$$
f_{3}(r)=0.5-0.16 r \text {. }
$$

The conclusion of the approximation procedure is:

$$
Q_{t}=Q_{0}-(0.5+0.16 r) t_{\mathrm{b}} / k_{m}-(0.5-0.16 r) t_{\mathrm{f}} / k_{m} \ldots(30)
$$

Thus, it can be understood that back tension has more of an effect on rolling load than front tension, and that this effect increases with increases in the degree of reduction.

\section{Experimental Study}

The rolling material was a lead strip, $150 \mathrm{~mm}$ wide and $1.9 \mathrm{~mm}$ thick. A 4 high mill with work rolls of $130 \mathrm{~mm}$ and back-up rolls of $300 \mathrm{~mm}$ in diameter was used for the experiment. Reduction was about $20 \%$. As can be seen from Fig. 7, which shows Eq. (30) and the relation between the tension and $Q_{t}$ of the experiment, $Q_{t}$ is obviously decreased by the tension, and Eq. (30) is satisfied.

\section{Tension Generated Shrinkage in Width of Strip}

Generally, tension generates shrinkage in the width of a strip, but it can also be used for width control. Therefore the influence of back and front tensions on the shrinkage of width was examined and shown in Fig. 8. In this figure, $\Delta b$ is the difference of delivery width $b_{2}$ and initial width $b_{0}$, white circles mean the case with back tension only (without front tension) and black circles mean the case with front tension only (without back tension). As can be seen from this figure, back tension $t_{\mathrm{b}}$ has more of an effect on the shrinkage can be ignored as long as tension is no more than about $0.5 \mathrm{~kg} / \mathrm{mm}^{2}$, tension changes up to this limit can be allowed in lead.

\section{Three-dimensional Deformation of Material Being Rolled}

As mentioned before, lead and hot steel have the same tendencies about material deformation. Accordingly, the three-dimensional deformation of a material being rolled is observed experimentally, and the behavior of strip crown change is clarified.

It would be ideal if the transverse thickness of a strip could be controlled as desired, but in practice, strips are rolled with various crowns. Actually, from the start of rolling to roll change, it is said that the crown changes more than $100 \mu$ in a day. This has made the desired control of the crown difficult.

Recently, a 6 high mill (the HC-mill) like that in

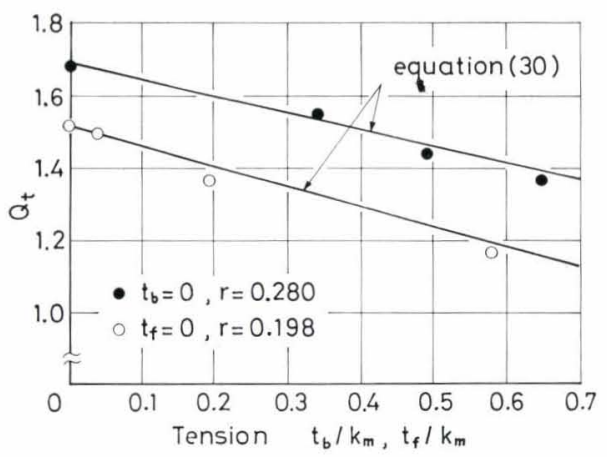

Fig. 7. Effect of tension on $Q_{t}$

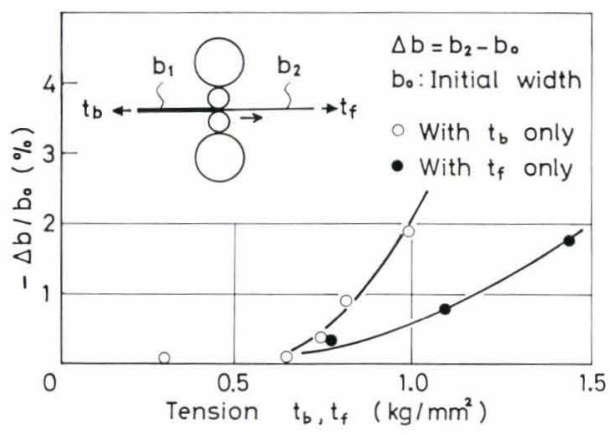

Fig. 8. Effect of tension on width change $\Delta b / b_{0}$

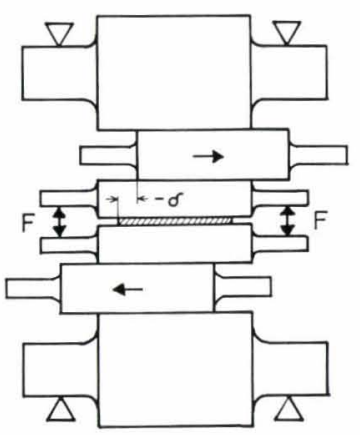

Fig. 9. The HC-mill

Fig. 9, with a function to change the curve of the contacting plane between a work roll and a material over a greater range than is possible with conventional 4 high mills, has been developed. ${ }^{6}$ ) This new mill opens up the possibility of controlling the strip crown.

\section{Experimental Method}

An HC-mill, whose details have already been reported ${ }^{6)}$ has a pair of intermediate rolls, which can move longitudinally across a strip, between the work and back-up rolls (Fig. 9). The diameters of the work, the intermediate and the back-up rolls of the experimental HC-mill were $100 \mathrm{~mm}, 130 \mathrm{~mm}$ and $300 \mathrm{~mm}$, respectively. The profile of all the rolls was flat. The material is a lead strip of $154 \mathrm{~mm}$ wide, $500 \mathrm{~mm}$ long and $4 \mathrm{~mm}$ thick, as rolled from an $8 \mathrm{~mm}$ thick strip purchased on the market. Changes in the dimensions of the strip in the rolling direction and across the width of the strip were obtained by measuring the distance between marker lines drawn on the strip surface, as shown in Fig. 10, before and 
after rolling.

Curves drawn to represent the transverse thicknesses of the two test pieces, A and B, before rolling, have the convex shapes shown in Fig. 11, the difference in thickness between the center and the edge of a test piece being about $50 \mu$. The rolling conditions were as follows.

Test piece A: $\delta=+100 \mathrm{~mm}, F=0 t /$ chock. The aim of this condition was to obtain a crown with maximum convexity.

Test piece B: $\delta=-50 \mathrm{~mm}, F=2 t /$ chock. The aim of this condition was to obtain a crown with maximum concavity.

A convex crown is rather easy to obtain, but it was not clear whether a convex crown could be readily changed to a concave one. The test with $\mathrm{B}$ was intended to clarify this problem. Tests were carried out with $30 \%$ reduction and without lubricants.

\section{Experimental Results}

\section{(1) Transverse Thickness}

As shown in Fig. 12 the transverse thicknesses of the test pieces $\mathrm{A}$ and $\mathrm{B}$ are different after rolling, and the crown of test piece $\mathrm{B}$ has become concave. Because the work sides of the test pieces shown in Fig. 12 were slightly thicker than the drive sides, due corrections were made. The results are shown in Fig. 13: a nearly flat profile is obtained for test piece A, and a concave crown of $30 \mu$ is obtained for B in spite of the convex crown of $50 \mu$ that was present before rolling. This suggests that the HC-mill can control a strip profile to within about $30 \mu$ of the desired thickness by means only of shifting the intermediate rolls, even in a small experimental mill. A convex crown can also be changed to a concave one, or a strip can even be given flat profile.

The broken line in Fig. 13 indicates the calculated roll profile. The thicknesses that were obtained in the experiments are in good agreement with this line. It will be noticed further that the profile of the strip crown, which was not very smooth before rolling, as can be seen from Fig. 11, was greatly smoothed out, and it indicates that compression strain may not be uniform across the width of a strip.

(2) Longitudinal Strain Distribution

Generally speaking, in cold rolling of steel, changes in the strip crown cause adverse changes in the strip shape. Therefore, this phenomenon is investigated in the case of lead.

The transverse distribution of longitudinal strain (strain in the rolling direction) after rolling is shown in Fig. 14. As far as this figure is concerned, elongation is nearly uniform, and distribution does not become very uneven as the shape changes.

Consequently, if the roll profile can be controlled in hot rolling, the strip crown can be changed without causing adverse changes in strip shape.

(3) Width Change

Figure 15 shows the transverse change $B_{2}-B_{1}$, where $B_{1}$ is the distance between marker lines before rolling and $B_{2}$ is the distance after rolling. The gradient of these curves indicates the degree of strain in a transverse direction, the positive gradient mean-

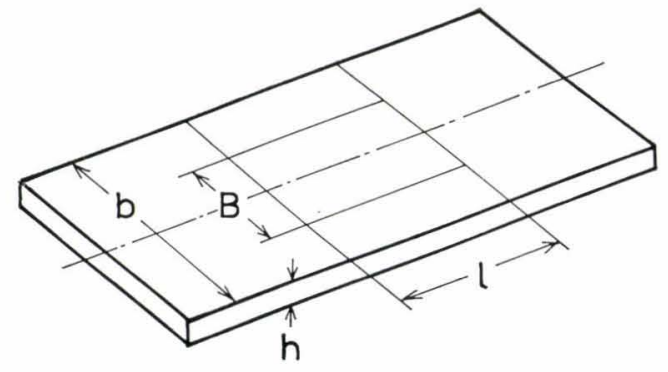

Subscript 1: before rolling

Subscript 2: after rolling

Fig. 10. Measuring points and symbols

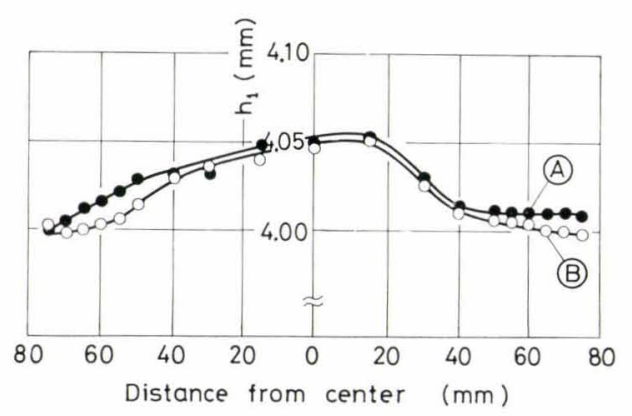

Fig. 11. Transverse thickness before rolling

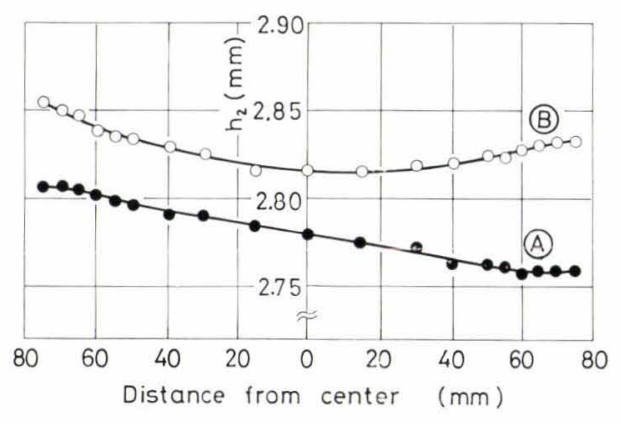

Fig. 12. Transverse thickness after rolling

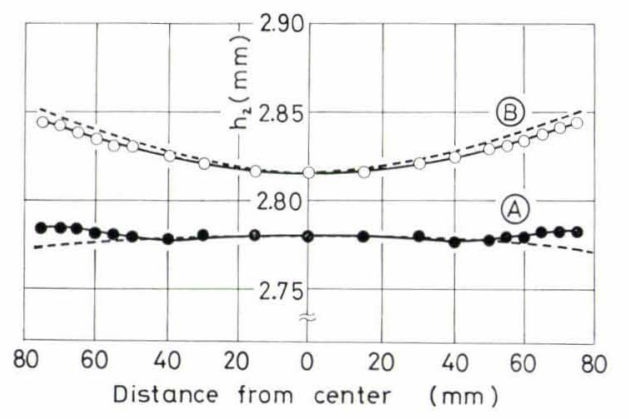

Fig. 13. Transverse thickness after correction of unsymmetry of Fig. 12

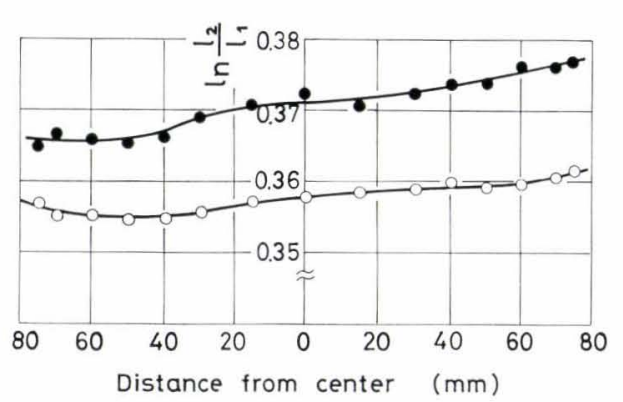

Fig. 14. Transverse distribution of longitudinal strain 


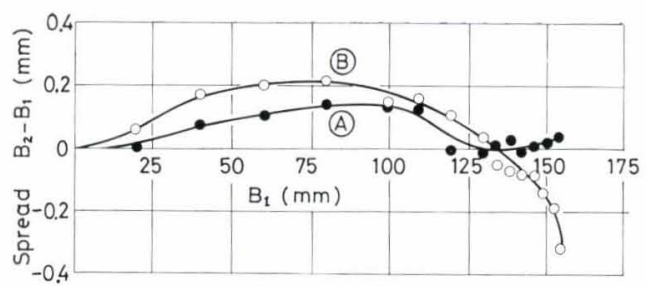

Fig. 15. Transverse distribution of spread

ing spread and the negative shrinkage. The following results are obtained from Fig. 15.

(1) In hot rolling, spread can be generated at the center even of thin strip. This is a very important phenomenon, which suggests that the strip crown can be easily controlled.

(2) Spread is not generated all across the width of a strip, instead spread and shrinkage exsist together. Especially, when reduction at the center of a strip is greater than at an edge, shrinkage occurs at the edge. Compared with the total reduction of $1300 \mu$ of a strip, the $50 \sim 80 \mu$ reduction of the crown may be very small, but even this small degree of reduction generates internal stress. When reduction at the center of a strip is greater than at an edge, the longitudinal stress at the center becomes a compression stress and that at the edge becomes tension. The edge may shrink with this tension.

(3) Although the reduction of both A and B test pieces is about the same $30 \%$, there is a large difference in the maximum spread (the change in the strip width at the edge of a strip): the spread of A was nearly zero, but $B$ shrink by about $0.2 \mathrm{~mm}$. It has been thought that changes in reduction and maximum spread occur at the same rate, but, as was observed above, even the small change of $50 \sim 80 \mu$ in the crown, when total reduction is $1300 \mu$, causes a large change in the maximum spread of a strip. The edge drop in this experiment was small, but in the case of hot steel where the edge drop is large, the relations between reduction and maximum spread will be more complicated.

\section{Summary}

The following conclusions are drawn from the simulation of the hot rolling process in which lead at room temperature was used as a model material.
(1) There are similarities in the rolling load and mean width of spread of lead and hot steel which qualify lead as a model material.

(2) The following theoretical formula is obtained as the rolling load function with tension in hot rolling.

$$
Q_{t}=Q_{0}-(0.5+0.16 r) t_{\mathrm{b}} / k_{m}-(0.5-0.16 r) t_{\mathrm{f}} / k_{m}
$$

The results obtained with the formula are shown to agree with the results obtained in the experimental simulation.

(3) The curve which represents transverse thickness is in a fairly good agreement with the roll profile, and this result indicates that changing the profile will allow the strip crown to be controlled. The HC-mill can control the roll profile by shifting the intermediate rolls appropriately.

(4) The deformation of a strip in transverse direction occurs easily in hot rolling. As spread can be generated even at the center of a strip, strip crown control is possible without adverse changes in strip shape.

These experimental simulations can be applied to various practical uses such as, for example, the development of mathematical models of the hot rolling process and of methods to control the strip crown.

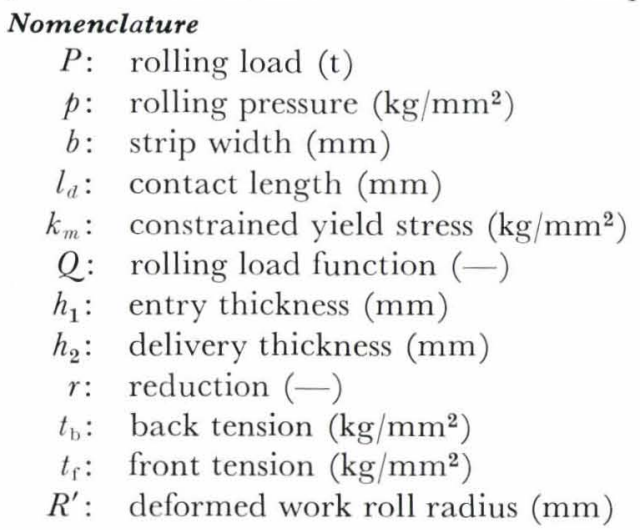

\section{REFERENCES}

1) R. Stewartson: Proc. Inst. Mech. Engr., 168 (1954), 201.

2) S. Shida: Hitachi Hyoron, 47 (1965), 1575.

3) L.G.M. Sparling: Proc. Inst. Mech. Engr., 175 (1961), 604.

4) S. Yanagimoto: Seisan Kenkyu, 13 (1961), 502.

5) R. B. Sims: Proc. Inst. Mech. Engr. 168 (1954), 191.

6) T. Kajiwara: Hitachi Review, 24 (1975), 341. 